\title{
A systematic review and meta-analysis of prevalence of insomnia in the third trimester of pregnancy
}

\author{
Nader Salari ${ }^{1,2}$, Niloofar Darvishi ${ }^{3}$, Behnam Khaledi-Paveh ${ }^{2}$, Aliakbar Vaisi-Raygani ${ }^{4}$, Rostam Jalali ${ }^{4}$,
} Alireza Daneshkhah ${ }^{5}$, Yalda Bartina ${ }^{6}$ and Masoud Mohammadi ${ }^{4^{*}}$ (D)

\begin{abstract}
Background: Sleep disorders, which are among the foremost important medical care issues, are prevalent in pregnancy. The present study is a meta-analysis of the prevalence of insomnia in the third trimester of pregnancy. This study aims to systematically review the overall prevalence of insomnia in the third trimester of pregnancy through conducting a meta-analysis.

Method: The literature used in this meta-analysis for the topic discussed above were obtained through searching several databases, including SID, Maglran, IranDoc, Scopus, Embase, Web of Science (WoS), PubMed Science Direct and Google Scholar databases without time limitation until December 2020. Articles developed based on crosssectional studies were included in the study. The heterogeneity of studies was investigated using the $I^{2}$ index. Also, the possible effects of heterogeneity in the studied studies are investigated using meta-regression analysis.

Result: In 10 articles and 8798 participants aged between11-40, the overall prevalence of insomnia in the third trimester of pregnancy based on meta-analysis was $42.4 \%$ (95\% Cl: 32.9-52.5\%). It was reported that as the sample size increases, the prevalence of insomnia in the third trimester of pregnancy increases. Conversely, as the year of research increases, the prevalence of insomnia in the third trimester of pregnancy decreases. Both of these differences were statistically significant $(P<0.05)$.

Conclusion: Insomnia was highly prevalent in the last trimester of pregnancy. Sleep disorders are neglected among pregnant women, and they are considered natural. While sleep disturbances can cause mental and physical problems in pregnant women, they can consequently cause problems for the fetus. As a result, maintaining the physical and mental health of pregnant mothers is very important. It is thus recommended that in addition to having regular visits during pregnancy, pregnant women should also be continuously monitored for sleep-related disorders.
\end{abstract}

Keywords: Insomnia, Pregnancy, Sleep disorder

\footnotetext{
* Correspondence: Masoud.mohammadi1989@yahoo.com

${ }^{4}$ Department of Nursing, School of Nursing and Midwifery, Kermanshah

University of Medical Sciences, Kermanshah, Iran

Full list of author information is available at the end of the article
}

(c) The Author(s). 2021 Open Access This article is licensed under a Creative Commons Attribution 4.0 International License, which permits use, sharing, adaptation, distribution and reproduction in any medium or format, as long as you give appropriate credit to the original author(s) and the source, provide a link to the Creative Commons licence, and indicate if changes were made. The images or other third party material in this article are included in the article's Creative Commons licence, unless indicated otherwise in a credit line to the material. If material is not included in the article's Creative Commons licence and your intended use is not permitted by statutory regulation or exceeds the permitted use, you will need to obtain permission directly from the copyright holder. To view a copy of this licence, visit http://creativecommons.org/licenses/by/4.0/ The Creative Commons Public Domain Dedication waiver (http://creativecommons.org/publicdomain/zero/1.0/) applies to the data made available in this article, unless otherwise stated in a credit line to the data. 


\section{Background}

Sleep is an essential physiological need for human beings, and it is also critical for their physical and physiological health [1]. Sleep disorders are considered to be the foremost important issues in medical care. They are generally classified as disturbed quality, poor sleep continuity, Restless Legs Syndrome, sleep disorder and sleep respiratory disorder [2]. Insomnia is a patient-reported compliant defined as difficulty in falling asleep or maintaining sleep, i.e., frequent awakening, difficulty returning to sleep after awakening, or awakening too early with inability to return to sleep [3]. Insomnia is the most common sleep complaint affecting $10-13 \%$ population chronically, and up to $35 \%$ of the population is experiencing some symptoms of insomnia [4]. A considerable quantity of studies reported that women complained more often of insomnia than men [5]. Pathophysiology and the time insomnia starts is not always clear [6]. Insomnia is typically diagnosed by recording nightly bedtime routine [7].

Pregnancy is one of the most crucial and critical stages in a woman's life. It brings tremendous changes in women's physiological, psychological and social life [1, 8]. Around $2 / 3$ of pregnant women consider their sleep pattern has become abnormal [9]. Depending on the women's body position and increase in their abdomen size, women can experience insomnia during pregnancy [10]. The association of sleep abnormality and pregnancy complications is biologically plausible [9]. Poor health outcomes resultinging from biological, and secretion modifications throughout pregnancy might be associated with sleep disturbances [2]. Sleep disturbances, which are common and prevalent in pregnancy, increase as pregnancy progresses [11]. In pregnancy, sleep changes with raised demand within the first trimester and additional difficulties within the last trimester [12]. In a study, Neau et al. (2009) reported that sleep alterations are common during pregnancy, yet the frequency of such alterations relies heavily on the trimester of pregnancy. Furthermore, Neau et al. [2009] maintain that more than $90 \%$ of patients involved in the study asserted that the quality of their sleep was good before pregnancy, but they experienced sleeping difficulty more and more as pregnancy proceeded [13].

A decrease in sleep quality and an increase in total sleep time have been frequently reported by pregnant women $[2,9]$. Insomnia in gestation is also caused by several reasons like physical illness, secretion changes, and fetus growth [1]. Insomnia causes deterioration in the quality of life; therefore, it becomes a significant problem throughout gestation for maternal and fetus health [1].
Considering the health benefits of good sleep for pregnant women, it is crucial to find ways to tackle the increasing prevalence of insomnia during the pregnancy and improve the sleep quality of this population [14]. The present study is a meta-analysis of the prevalence of insomnia in the third trimester of pregnancy.

\section{Methods}

\section{Search strategy}

This study is a systematic review and meta-analysis based on the findings of previous studies conducted on the prevalence of insomnia in the third trimester of pregnancy, including articles published in domestic and foreign journals obtained by searching at Scopus, Embase, Science Direct, Web of Science (WoS), SID, Mag Iran, Medline (PubMed), IranDoc and Google Scholar until December 2020.

The search process was performed in Persian and English databases using keywords, including disorders of initiating and maintaining sleep, insomnia, pregnancy and third trimester. The AND/OR operators were also used in this study to provide more comprehensive access to all articles. Therefore, the AND/OR operator was used to check the disorder's common names by matching words in the MeSH browser.

PubMed search strategy: (((((Sleep [Title/Abstract]) OR Sleep Habits [Title/Abstract]) AND Insomnia [Title/ Abstract]) OR Sleep Initiation and Maintenance Disorders OR Sleep Habits [Title/Abstract]) OR Chronic Insomnia [Title/Abstract]) OR Disorders of Initiating and Maintaining Sleep [Title/Abstract]) OR DIMS [Title/Abstract]) OR Nonorganic Insomnia [Title/Abstract]) OR Primary Insomnia [Title/Abstract]) OR Psychophysiological Insomnia [Title/Abstract]) OR Sleeplessness [Title/Abstract]) OR Insomnia Disorder [Title/Abstract]) AND Pregnancy [Title/Abstract]) OR Pseudopregnancy [Title/Abstract]) OR Pregnant Women [Title/Abstract]) AND Third Trimester of Pregnancy [Title/Abstract]) OR Pregnancy Trimester, Third [Title/Abstract]) OR Last Trimester [Title/Abstract] ))))).

\section{Inclusion and exclusion criteria}

The studies' inclusion criteria include 1- Cross-sectional studies, 2- population-based study, 3-studies that have examined insomnia in the third trimester of pregnancy, 4- analytical descriptive studies (non-interventional studies), and 5- studies in the English language.

Exclusion criteria of the studies include 1- casecontrol studies, 2- case report, 3- interventional studies, 4-letter to the editor, 5- studies with no full-text availability 6- studies not related to the subject, 7- studies without sufficient data, 8- repetition of studies, and 9review studies. 
Criteria for selection and evaluation of articles and quality assessment

In order to maximize the comprehensiveness of the search, the list of sources used in all related articles found in the above search was manually reviewed. Initially, studies that were repeated in various databases searched were removed from this study. Then, a list of all the remaining articles' titles was prepared to get qualified articles by evaluating the articles in this list.

In the first stage, duplicate publication and multiple publications from the same population were removed using EndNore citation management software (version X7, for Windows, Thomson Reuters).

The title and abstract of the remaining articles were carefully studied in the next step, and unrelated articles were removed according to the inclusion and exclusion criteria. In the third stage, i.e. the evaluation of the competence of the studies, the full text of the possible related articles remaining from the screening stage was examined based on the inclusion and exclusion criteria, and unrelated studies were also removed in this stage. To prevent bias, all sources of resource review and data extraction were performed by two researchers independently. If the articles were not included, the reason for deleting them was mentioned. In cases where there was a disagreement between two researchers, a third person would review the article.

In the final stage, the quality of the studies was examined, and the STROBE checklist was used to review the studies. This checklist contains 22 sections, 18 of which are general and practical for all observational studies, including cohort, case study, and cross-sectional ones.

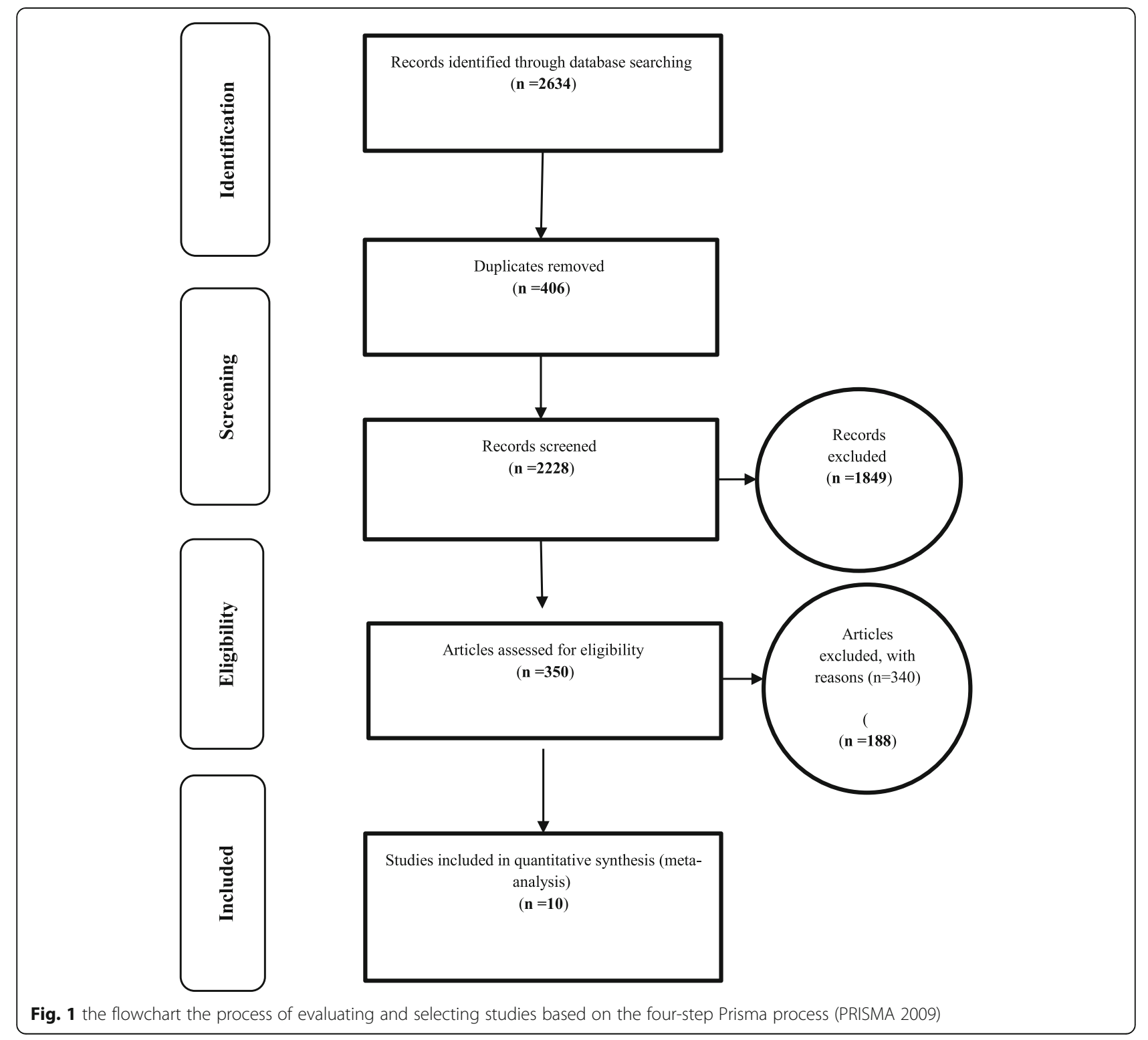


Table 1 Specifications and information extracted from studies entered into the meta-analysis stage

\begin{tabular}{|c|c|c|c|c|c|c|c|}
\hline Row & Author & $\begin{array}{l}\text { Publication } \\
\text { year }\end{array}$ & Area & $\begin{array}{l}\text { Participants' } \\
\text { Age }\end{array}$ & $\begin{array}{l}\text { Sample } \\
\text { size }\end{array}$ & Prevalence & Assessing and defining sleep disorders \\
\hline 1 & $\begin{array}{l}\text { Cai, X. H } \\
\text { [15]. }\end{array}$ & 2013 & China & - & 1993 & $32.01 \%$ & $\begin{array}{l}\text { Sleep status of the married women was conducted using the } \\
\text { Berlin Questionnaire. They adapted a few other items according } \\
\text { to the characteristics of the pregnant women in their study. }\end{array}$ \\
\hline 2 & $\begin{array}{l}\text { Dørheim, } \\
\text { S. K [12] }\end{array}$ & 2012 & Norway & $30.9( \pm 4.8)$ & 2816 & $61.9 \%$ & Insomnia was measured by the Bergen Insomnia Scale. \\
\hline 3 & $\begin{array}{l}\text { Dørheim, } \\
\text { S. K [10] }\end{array}$ & 2014 & Norway & $\begin{array}{l}31.5( \pm 4.7 \\
\text { range } \\
17.4-45.7)\end{array}$ & 2088 & $61.6 \%$ & The Bergen Insomnia Scale (BIS) was used to measure insomnia \\
\hline 4 & $\begin{array}{l}\text { Facco, F. L. } \\
{[9]}\end{array}$ & 2010 & America & $29.7( \pm 5.5)$ & 189 & $54.3 \%$ & $\begin{array}{l}\text { The survey was composed of the following validated sleep } \\
\text { questionnaires: Berlin Questionnaire for Sleep Disordered } \\
\text { Breathing, Epworth Sleepiness Scale, National Institutes of Health/ } \\
\text { International Restless Legs Syndrome Question Set, Women's } \\
\text { Health Initiative Insomnia Rating Scale, and the Pittsburgh Sleep } \\
\text { Quality Index. }\end{array}$ \\
\hline 5 & $\begin{array}{l}\text { Kizilirmak, } \\
\text { A [1]. }\end{array}$ & 2012 & Turkey & $25.2 \pm 5.49$ & 281 & $30.24 \%$ & $\begin{array}{l}\text { developed Women's Health Initiative Insomnia Rating Scale } \\
\text { (WHIIRS): } \\
\text { The scale is a 5-point Likert type in which the first } 4 \text { questions } \\
\text { aim to identify the beginning of insomnia, sleep-maintenance } \\
\text { insomnia, and the state of waking up early in the mornings, while } \\
\text { the last question is associated with quality of sleep. "0" score } \\
\text { indicates that there is no problem in relation to insomnia, } \\
\text { while " } 4 \text { " indicates that there are problems in relation to } \\
\text { insomnia for } 5 \text { or more times in a week. The highest score } \\
\text { obtained from the scale demonstrated the highest levels of } \\
\text { insomnia symptoms. }\end{array}$ \\
\hline 6 & $\begin{array}{l}\text { Khazaie, } \mathrm{H} \\
{[2] .}\end{array}$ & 2013 & Iran & $25.3 \pm 5.5$ & 106 & $12.3 \%$ & Global sleep assessment questionnaire (GSAQ) \\
\hline 7 & $\begin{array}{l}\text { Lopes, E. A } \\
{[16] .}\end{array}$ & 2004 & Brazil & $11-40$ & 300 & $39 \%$ & $\begin{array}{l}\text { The survey was composed by brief clinical interview based on } \\
\text { directed questions. An anamnesis was performed according to } \\
\text { the following questions, always considering the PG state: 1) Do } \\
\text { you have any difficulty to fall asleep when you lie down in bed? } \\
\text { 2) Do you wake up too early in the morning (earlier than you are } \\
\text { supposed to)? 3) If you wake up during the night, do you find it } \\
\text { difficulty to sleep again? 4) Has anyone ever told you that you } \\
\text { snore? 5) Has anybody ever said that you have difficulty in } \\
\text { breathing during the night (like stop breathing)? 6) Do you } \\
\text { suddenly fall asleep during the day or in the middle of some kind } \\
\text { of activity? 7) Do you fall asleep anywhere (as on buses, in the } \\
\text { classroom, at work or while driving)? 8) Do you feel sleepy during } \\
\text { the day? 9) Have you been taking naps during the day? 10) Do } \\
\text { you wake up with the baby movements? 11) Do you wake up } \\
\text { because of abdominal pains or contractions? 12) Do you wake up } \\
\text { due to dreams or nightmares involving the baby or to childbirth? } \\
\text { 13) Do you wake up with heartburn? }\end{array}$ \\
\hline 8 & $\begin{array}{l}\text { Wolynczyk- } \\
\text { Gmaj, D } \\
\text { [17]. }\end{array}$ & 2017 & Poland & $30.6 \pm 5$ & 266 & $39.8 \%$ & $\begin{array}{l}\text { The assessment of variables was performed using the Athens } \\
\text { Insomnia Scale (AIS), Beck Depression Inventory (BDI), Regestein } \\
\text { Hyperarousal Scale (HS), Epworth Sleepiness Scale (ESS), General } \\
\text { Practice Physical Activity Questionnaire, and a semi-structured } \\
\text { interview about different sleep disorders }\end{array}$ \\
\hline 9 & $\begin{array}{l}\text { Bondad, R } \\
{[18] .}\end{array}$ & 2004 & Iran & $12.87 \pm 4.86$ & 320 & $57.81 \%$ & Check the sleep pattern test (Sleep-log) \\
\hline 10 & $\begin{array}{l}\text { Okun, M. L } \\
{[19]}\end{array}$ & 2018 & America & $28.8 \pm 6.3$ & 439 & $33.25 \%$ & $\begin{array}{l}\text { The ISQ instrument designed to identify insomnia. The ISQ is a } \\
\text { 13-item self-report instrument which questions are based on } \\
\text { DSM-IV criteria for primary insomnia and are consistent with the } \\
\text { American Academy of Sleep Medicine's (AASM) Research } \\
\text { Diagnostic Criteria (RDC). }\end{array}$ \\
\hline
\end{tabular}




\section{Funnel Plot of Standard Error by Logit event rate}

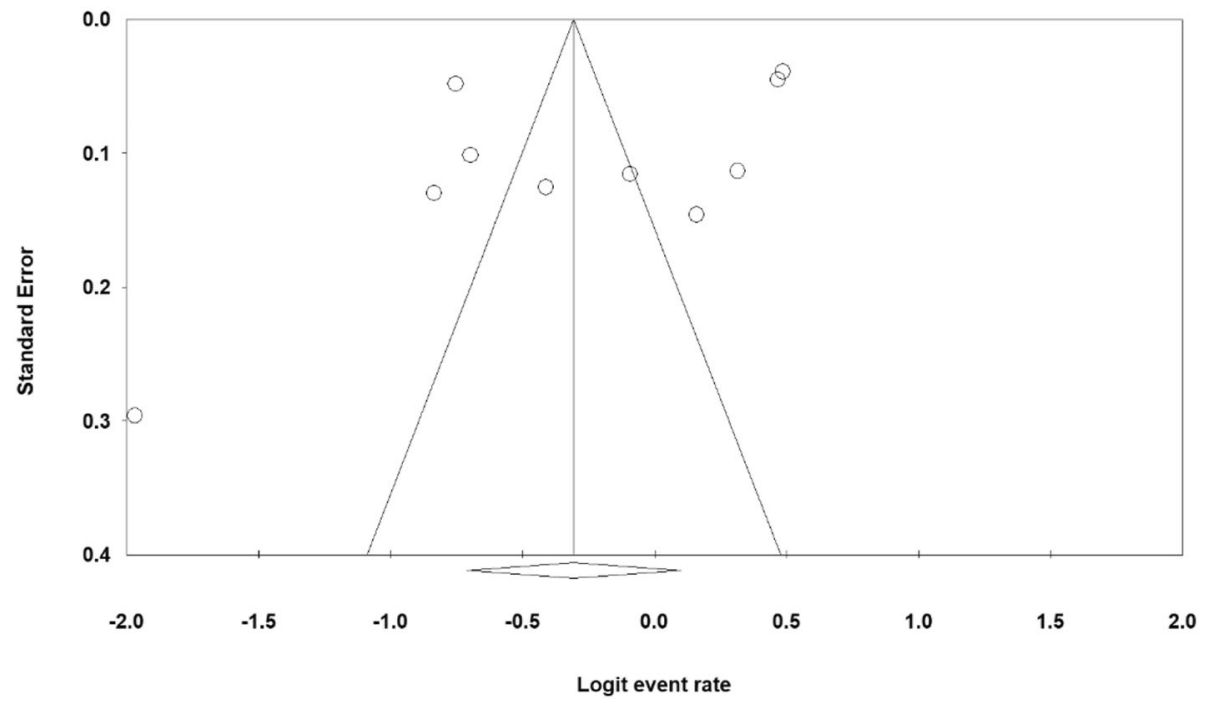

Fig. 2 Funnel plot and review of publication bias for the results of the prevalence of insomnia in third trimester of pregnancy

Accordingly, the maximum quality score of 32 was considered, and papers with a score of less than 14 were considered to have low quality, and they were thus excluded from the study.

\section{Statistical analysis}

In each study, the prevalence of insomnia in the third trimester of pregnancy was obtained. The heterogeneity of the studies was evaluated using the $\mathrm{I}^{2}$ test. Generally, heterogeneity is classified into three categories: heterogeneity $>25 \%$ (low heterogeneity), 25-75\% (average heterogeneity), and $75 \%$ > higher (high heterogeneity). In order to review the analysis of the studies, it was decided based on the results of heterogeneity. If the heterogeneity was less than 20, the method of fixed effects was used, and if it was higher, the method of random effects was used. Egger's test was used to statistically analyze the publication bias and the significance level of 0.05 . The probability of publication bias in results was shown using the funnel plot. Also, the possible effects of heterogeneity in the studied studies were investigated using meta-regression analysis. The data were analyzed using the Comprehensive Meta-Analysis (Biostat, Englewood, NJ, USA Version 3).

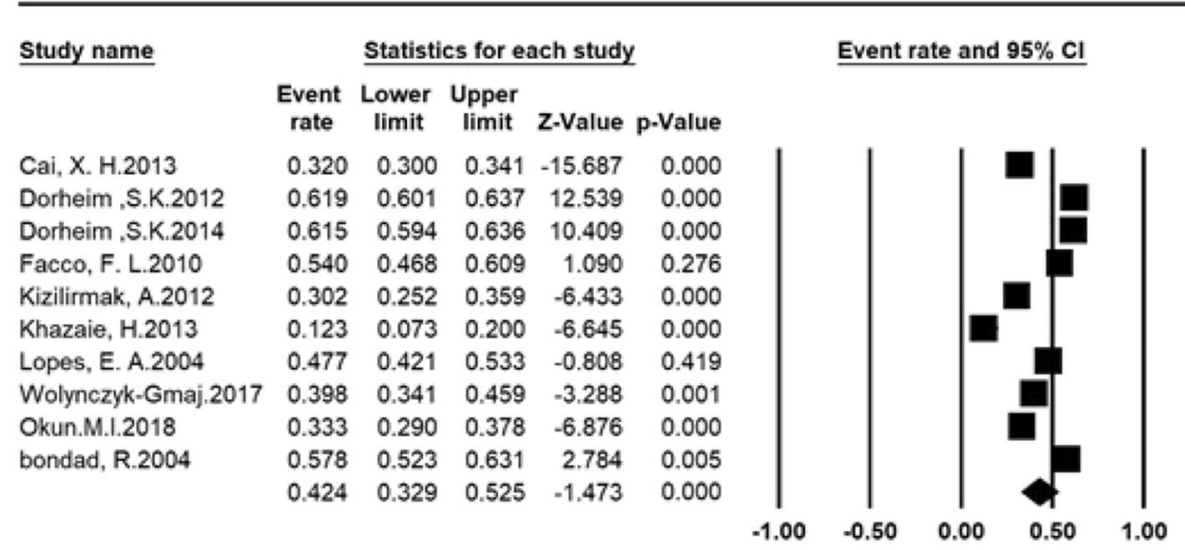

Meta Analysis

Fig. 3 Forrest Plot and Determination overall prevalence of insomnia in third trimester of pregnancy based on the random effects model 


\section{Regression of Sample on Logit event rate}

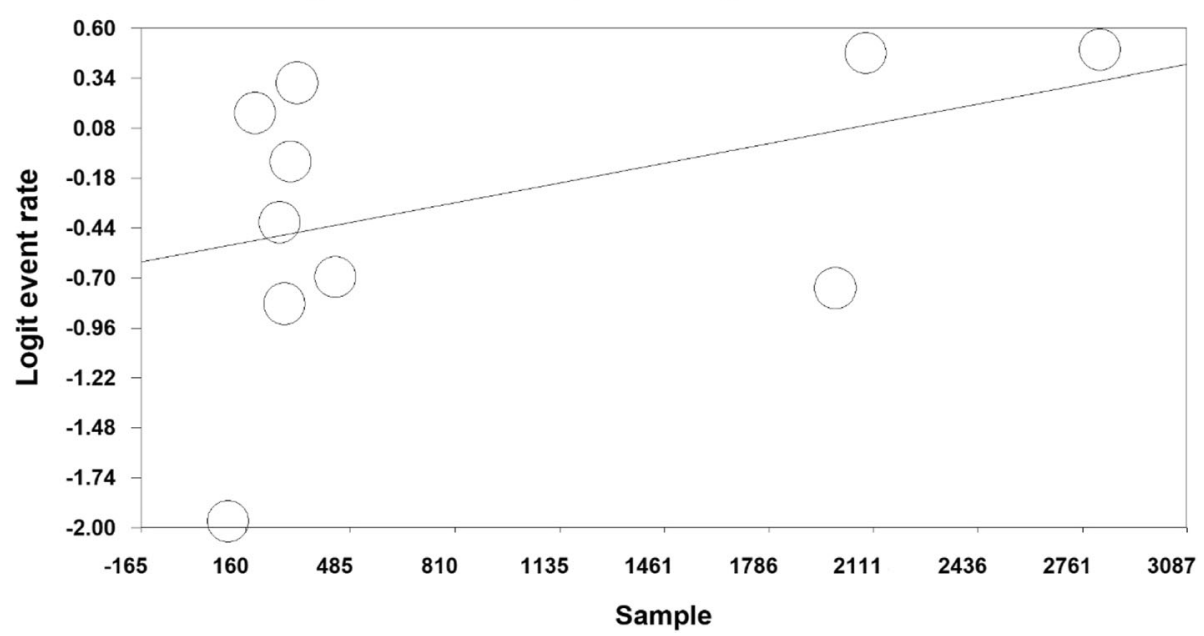

Fig. 4 The effect of sample size of studies on the prevalence of insomnia in the third trimester of pregnancy based on meta-regression analysis

\section{Results}

Based on studies on the prevalence of insomnia in the third trimester of pregnancy that included articles published in domestic or foreign journals (Fig. 1), articles that met the initial inclusion criteria were included in the study. In the second step, based on the primary assessments and exclusion of 406 duplicate ones, a total of 2228 articles remained. A further 350 articles were eliminated as they were unrelated to the subject of the study and 18 articles in a secondary assessment due to the lack of access to their abstract and full text as well as their poor quality. Therefore eventually 10 articles were entered in the metaanalysis process (Table 1). The heterogeneity of the studies was evaluated using the $\mathrm{I}^{2}$ test that its value was $98.6 \%$, thus the random-effects model was used to combine the results of the studies. The publication bias was not statistically significant $(P=0.371)$ (Fig. 2$)$.

The total number of participants in this study was 8798 individuals aged between 11 and 40 years old, and the overall prevalence of insomnia in the third trimester of pregnancy was $42.4 \%$ (95\% CI: 32.9-52.5\%) (Fig. 3). As shown in Fig. 4, as the sample size increases, the prevalence of insomnia increases in the third trimester, which is statistically significant $(P<0.05)$. In Fig. 5 , it is also shown that with an increase in the number of years of research, the prevalence of insomnia in the third trimester was reduced, and this was also statistically significant $(P<0.05)$.

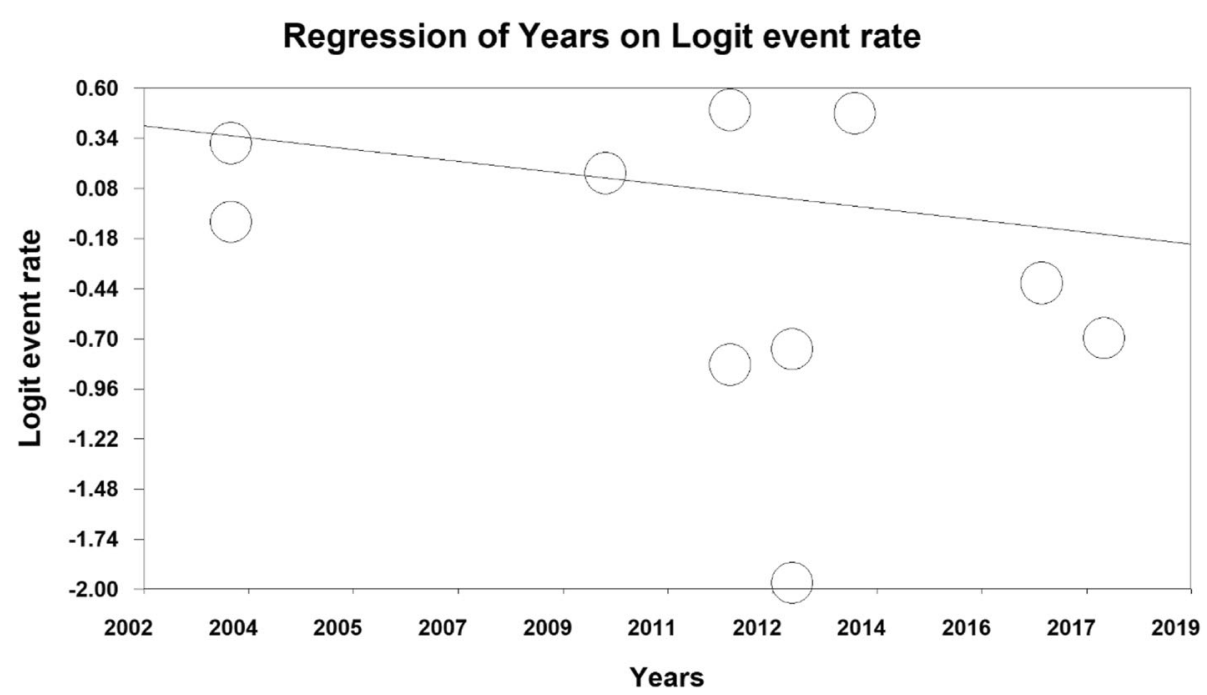

Fig. 5 The effect of publication year of studies on the prevalence of insomnia in the third trimester of pregnancy based on meta-regression analysis 


\section{Discussion}

This study aimed to determine the prevalence of insomnia during the third trimester of pregnancy. Our systematic review of published epidemiologic studies confirmed a $42.4 \%$ prevalence of insomnia in the third trimester of pregnancy. It is the first meta-analysis conducted on the prevalence of insomnia in late pregnancy to the best of our knowledge. In total, we have used ten studies in this meta-analysis to address the purposes of this study.

Pregnant women often experience insomnia. The prevalence of this complication in early pregnancy is between 12 to $38 \%$, which increases to $60 \%$ in the third trimester [20]. According to the results of the study by Osnes,. et al. (2020), 60\% of the study population has experienced mid-pregnancy insomnia and $55 \%$ of these individuals have experienced postpartum insomnia [20]. In a meta-analysis conducted in 2020 , the overall prevalence of insomnia symptoms in the study population was $38.2 \%$. According to a study by Felder et al. (2020), approximately $40 \%$ of 117 individuals in the study population experienced moderate to severe insomnia symptoms. According to the results of this study, the prevalence of insomnia did not differ in different trimesters of pregnancy, but this complication was more common in women with children compared to women who did not have children [21].

Natural biological changes may play a vital role in the development of insomnia in pregnant women. Women who are prone to insomnia may, for example, have more difficulty in falling asleep after waking up at the midnight due to stressors related to pregnancy [22]. Various factors might be associated with insomnia in pregnancy of that age of pregnant woman, gestational age, pregnancy trimester, symptoms of anxiety and depression, level of education, and personality traits are among these factors [22, 23]. Mid-pregnancy insomnia was associated with the occurrence of depression but was not significantly associated with postpartum depression [20]. Previous background of insomnia is the most important factor in developing this complication during pregnancy [24].

Sleep alterations and daytime sleepiness are commonly reported during pregnancy, but their frequency depends on the trimester of pregnancy [13].

As the pregnancy progresses, the rate of insomnia increases and then decreases significantly after delivery [24]. Many studies have reported that sleep quality deteriorates during pregnancy and is often most disturbed in the third trimester [22]. According to a study by Wolynczyk-Gmaj et al. (2017), the prevalence of insomnia in the third trimester of pregnancy was reported as $39.8 \%$. Roman-Galvez et al. (2018), reported that the prevalence of insomnia in the first, second and third trimesters was $44.2,46.3$, and $63.7 \%$, respectively. According to this study, obesity of pregnant woman, occupational status of pregnant women and previous background of insomnia were introduced as factors related to the high prevalence of insomnia during pregnancy [24].

In a similar study conducted in Poland and reported in Wolynczyk et al. (2017), the prevalence of insomnia in the third trimester of pregnancy was reported to be $39.8 \%$ [17]. In another study conducted in Iran, the prevalence of insomnia within the third trimester of gestation was reported to be $57.81 \%$. This study presented insomnia as the most common disorder within the third trimester of pregnancy [18]. Another study in Norway reported an incidence of $61.9 \%$ in the third trimester of pregnancy [12]. Likewise, in another study by the same author two years later showed that the incidence of insomnia was $61.6 \%$ [23].

Considering the results of the present study obtained from the examination of 8798 individuals with the age range of 11-40, the overall prevalence of insomnia in the third trimester of pregnancy was $42.4 \%$ that is based on the meta-analysis. Moreover, the results obtained from meta-regression reported that the prevalence of insomnia in the third trimester of pregnancy increases with increased sample size and reduces as the number of years increases that were both statistically significant.

\section{Limitations}

The most important limitations of the present study were related to the inaccessibility of the full-text of some retrieved studies and the lack of information required in some studies.

\section{Conclusions}

Sleep disturbances can cause mental and physical problems in pregnant women as well as problems for the fetus. As a result, maintaining the physical and mental health of pregnant mothers is of great importance. It is thus recommended that in addition to having regular visits during pregnancy, pregnant women should also be continuously monitored for sleep-related disorders. Appropriate counselling programs to prevent and treat sleep disorders should be then provided. This will take a step towards ensuring the health of pregnant mothers, their babies, and ultimately, the health of the whole community.

\section{Abbreviations}

SID: Scientific Information Database; WoS: Web of Science; PRISMA: Preferred Reporting Items for Systematic Reviews and Meta-Analysis.; STROBE: Strengthening the Reporting of Observational Studies in Epidemiology for cross-sectional study

\section{Acknowledgements}

We hereby express our gratitude and appreciation to the Student Research Committee of Kermanshah University of Medical Sciences. 


\section{Authors' contributions}

ND and NS and BKP contributed to the design, MM and RJ statistical analysis, participated in most of the study steps. AVR and ND and MM prepared the manuscript. NS, AD, MM, and YB assisted in designing the study, and helped in the, interpretation of the study. All authors have read and approved the content of the manuscript.

\section{Funding}

By Student Research Committee of Kermanshah University of Medical Sciences, Deputy for Research and Technology, Kermanshah University of Medical Sciences (IR) (980817). the deputy of research and technology Kermanshah University of Medical Sciences had no role in the design of the study and collection, analysis, and interpretation of data and in writing of the manuscript.

\section{Availability of data and materials}

Datasets are available through the corresponding author upon reasonable request.

\section{Declarations}

\section{Ethics approval and consent to participate}

Ethics approval was received from the ethics committee of deputy of research and technology, Kermanshah University of Medical Sciences (IR.KUMS.REC.1398.737).

\section{Consent for publication}

Not applicable.

\section{Competing interests}

The authors declare that they have no conflict of interest.

\section{Author details}

'Department of Biostatistics, School of Health, Kermanshah University of Medical Sciences, Kermanshah, Iran. ${ }^{2}$ Sleep Disorders Research Center, Kermanshah University of Medical Sciences, Kermanshah, Iran. ${ }^{3}$ Student Research Committee, Kermanshah University of Medical Sciences, Kermanshah, Iran. ${ }^{4}$ Department of Nursing, School of Nursing and Midwifery, Kermanshah University of Medical Sciences, Kermanshah, Iran. ${ }^{5}$ School of Computing, Electronics and Maths, Coventry University, London, UK. ${ }^{6}$ Department of Translation Studies, Faculty of Literature, Istanbul University, Istanbul, Turkey.

Received: 8 July 2020 Accepted: 24 March 2021

Published online: 09 April 2021

\section{References}

1. Kizilirmak A, Timur S, Kartal B. Insomnia in pregnancy and factors related to insomnia. TheScientificWorldJournal. 2012;2012:197093.

2. Khazaie H, Heidarpour A, Nikray R, Rezaei M, Maroufi A, Moradi B, et al. Evaluation of sleep problems in preeclamptic, healthy pregnant and nonpregnant women. Iran J Psychiatry. 2013;8(4):168-71.

3. Buysse DJ. Insomnia. Jama. 2013;309(7):706-16. https://doi.org/10.1001/ja ma.2013.193.

4. Flynn-Evans EE, Shekleton JA, Miller B, Epstein L, Kirsch D, Brogna LA, et al. Circadian phase and phase angle disorders in primary insomnia. Sleep. 2017:40(12):1-11.

5. Zhang B, Wing YK. Sex differences in insomnia: a meta-analysis. Sleep. 2006; 29(1):85-93. https://doi.org/10.1093/sleep/29.1.85.

6. Ebben MR, Kapella MC. Insomnia. Am J Respir Crit Care Med. 2014;190(12): 9-10.

7. Incze M, Redberg RF, Gupta A. I have insomnia-what should I do? JAMA Intern Med. 2018;178(11):1572. https://doi.org/10.1001/jamainternmed.2018.2 626.

8. Darvishi N, Daneshkhah A, Khaledi-Paveh B, Vaisi-Raygani A, Mohammadi M, Salari $N$, et al. The prevalence of restless legs syndrome/Willis-ekbom disease (RLS/WED) in the third trimester of pregnancy: a systematic review. BMC Neurol. 2020;20(1):132. https://doi.org/10.1186/s12883-020-01709-0.

9. Facco FL, Kramer J, Ho KH, Zee PC, Grobman WA. Sleep disturbances in pregnancy. Obstet Gynecol. 2010;115(1):77-83. https://doi.org/10.1097/AOG. 0b013e3181c4f8ec.
10. Dorheim SK, Bjorvatn B, Eberhard-Gran M. Can insomnia in pregnancy predict postpartum depression? A longitudinal, population-based study. PLoS One. 2014;9(4):e94674. https://doi.org/10.1371/journal.pone.0094674.

11. Cain MA, Brumley J, Louis-Jacques A, Drerup M, Stern M, Louis JM. A pilot study of a sleep intervention delivered through group prenatal care to overweight and obese women. Behav Sleep Med. 2020;18(4):477-87. https://doi.org/10.1080/15402002.2019.1613995.

12. Dorheim SK, Bjorvatn B, Eberhard-Gran M. Insomnia and depressive symptoms in late pregnancy: a population-based study. Behav Sleep Med. 2012;10(3):152-66. https://doi.org/10.1080/15402002.2012.660588.

13. Neau JP, Texier B, Ingrand P. Sleep and vigilance disorders in pregnancy. Eur Neurol. 2009;62(1):23-9. https://doi.org/10.1159/000215877.

14. Borodulin K, Evenson KR, Monda K, Wen F, Herring AH, Dole N. Physical activity and sleep among pregnant women. Paediatr Perinat Epidemiol. 2010;24(1):45-52. https://doi.org/10.1111/j.1365-3016.2009.01081.x.

15. Cai XH, Xie YP, Li XC, Qu WL, Li T, Wang HX, et al. The prevalence and associated risk factors of sleep disorder-related symptoms in pregnant women in China. Sleep Breath. 2013;17(3):951-6.

16. Lopes EA, Carvalho LB, Seguro PB, Mattar R, Silva AB, Prado LB, et al. Sleep disorders in pregnancy. Arq Neuropsiquiatr. 2004;62(2a):217-21. https://doi. org/10.1590/50004-282X2004000200005.

17. Wolynczyk-Gmaj D, Rozanska-Waledziak A, Ziemka S, Ufnal M, Brzezicka A, $G$ maj $B$, et al. Insomnia in pregnancy is associated with depressive symptoms and eating at night. J Clin Sleep Med. 2017;13(10):1171-6. https://doi.org/10.5664/jcsm.6764.

18. Bondad R, Abedian Z. Factors affecting sleep pattern of pregnant women in 3rd trimester. Iran J Nurs. 2004;16(36):22-6.

19. Okun ML, O'Brien LM. Concurrent insomnia and habitual snoring are associated with adverse pregnancy outcomes. Sleep Med. 2018;46:12-9. https://doi.org/10.1016/j.sleep.2018.03.004.

20. Osnes RS, Eberhard-Gran M, Follestad T, Kallestad H, Morken G, Roaldset JO. Mid-pregnancy insomnia and its association with perinatal depressive symptoms: a prospective cohort study. Behav Sleep Med. 2020:1-18. https:// doi.org/10.1080/15402002.2020.1743705.

21. Felder JN, Hartman AR, Epel ES, Prather AA. Pregnant patient perceptions of provider detection and treatment of insomnia. Behav Sleep Med. 2020;18(6): 787-96. https://doi.org/10.1080/15402002.2019.1688153.

22. Sedov ID, Anderson NJ, Dhillon AK, Tomfohr-Madsen LM. Insomnia symptoms during pregnancy: a meta-analysis. J Sleep Res. 2021;30(1): e13207. https://doi.org/10.1111/jsr.13207.

23. Dorheim SK, Garthus-Niegel S, Bjorvatn B, Eberhard-Gran M. Personality and perinatal maternal insomnia: a study across childbirth. Behav Sleep Med. 2016;14(1):34-48. https://doi.org/10.1080/15402002.2014.941063.

24. Roman-Galvez RM, Amezcua-Prieto C, Salcedo-Bellido I, Martinez-Galiano JM, Khan KS, Bueno-Cavanillas A. Factors associated with insomnia in pregnancy: a prospective cohort study. Eur J Obstetrics Gynecol Reprod Biol. 2018;221:70-5. https://doi.org/10.1016/j.ejogrb.2017.12.007.

\section{Publisher's Note}

Springer Nature remains neutral with regard to jurisdictional claims in published maps and institutional affiliations.

Ready to submit your research? Choose BMC and benefit from:

- fast, convenient online submission

- thorough peer review by experienced researchers in your field

- rapid publication on acceptance

- support for research data, including large and complex data types

- gold Open Access which fosters wider collaboration and increased citations

- maximum visibility for your research: over $100 \mathrm{M}$ website views per year

At BMC, research is always in progress.

Learn more biomedcentral.com/submission 